\title{
Special issue on 4th ACPA
}

\author{
Sakae Shibusawa
}

Published online: 22 December 2013

(C) Springer Science+Business Media New York 2013

I would like to express my appreciation to the 18 paper authors and more than 40 reviewers, as well as Dr. J. Stafford as the editor-in-chief and Dr. J. Schepers as the coeditor-in-chief, for their great efforts. After the peer review, three papers were accepted. Rejection was due to out of scope, irregular format, insufficient originality and weak critical discussion. I would like to emphasize that all researchers in Asian countries try to create and submit original papers to Precision Agriculture.

March 11th, 2011, was the day when NE Japan was attacked by the tri-disaster: M 9.0 super earthquake, 10-m high Tsunami and the Fukushima nuclear power station accident. During the rescue and recovery from the disaster, 4 ACPA was held in Obihiro, Japan. Systems approaches to recovering from disaster will be an important issue to be faced in the coming years for Asian countries. The guest editor also much appreciates the help and sympathy from all over the world.

\footnotetext{
S. Shibusawa $(\bowtie)$

Department of Environmental and Agricultural Engineering, Tokyo University of Agriculture and Technology, 3-5-8 Saiwai-cho, Fuchu, Tokyo 183-8509, Japan e-mail: sshibu@cc.tuat.ac.jp
} 